\title{
Cross Border Abatement and its Welfare Effects
}

\section{Max Planck Institute for Tax Law and Public Finance}

Working Paper 2013 - 04

August 2013

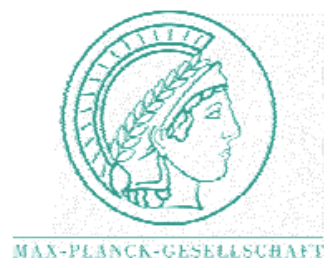

Max Planck Institute for Tax Law and Public Finance

Department of Business and Tax Law

Department of Public Economics

http://www.tax.mpg.de 
Working papers of the Max Planck Institute for Tax Law and Public Finance Research Paper Series serve to disseminate the research results of work in progress prior to publication to encourage the exchange of ideas and academic debate. Inclusion of a paper in the Research Paper Series does not constitute publication and should not limit publication in any other venue. The preprints published by the Max Planck Institute for Tax Law and Public Finance represent the views of the respective author(s) and not of the Institute as a whole. Copyright remains with the author(s).

Max Planck Institute for Tax Law and Public Finance

Marstallplatz 1

D-80539 Munich

Tel: $\quad+498924246-0$

Fax: $\quad+498924246-501$

E-mail: ssrn@tax.mpg.de

http://www.tax.mpg.de 


\title{
Cross Border Abatement and its Welfare Effects
}

\author{
Sabine Aresin*
}

August 7, 2013

\begin{abstract}
This paper examines the Clean Development Mechanism (CDM) of the Kyoto Protocol and its welfare implications for the countries engaging in it. It uses a simultaneous public good game, the public good being emission abatement, to asses the impact of the CDM on the public good provision equilibrium and on the countries' welfare. Three different cases are considered in this paper. First, a benchmark case without CDM is presented. This is followed by two cases with CDM, which differ in their cost functions: in one a preferential right for emission abatement is granted to Annex I, in the other to Non-Annex I countries. In general, the CDM is welfare increasing, but welfare under the CDM depends on who is granted the preferential right.

Keywords: Private Provision of a Public good, Clean Development Mechanism, Abatement, Environmental Public Goods
\end{abstract}

JEL classification: F53, H41, Q58

*Max Planck Institute for Tax Law and Public Finance, Department of Public Economics, Marstallplatz 1, 80539 Munich, Germany, phone: 00498924246 5257, e-mail: sabine.aresin@tax.mpg.de. 


\section{Introduction}

In international climate policy, the Kyoto Protocol marks a milestone for the global coordination on fighting Green House Gas (GHG) induced climate change. This paper analyzes a special feature of the Kyoto Protocol, the Clean Development Mechanism (CDM). After the European Union Emission Trading System, the CDM is the world's second largest market for emission permits, both with respect to usage and issuance of emission permits. ${ }^{1}$ The CDM enables industrialized countries to abate Green House Gas emissions, not only at home but also in developing or emerging countries, abroad. Emission credits, which industrialized countries earn for their abatement abroad, can be counted against the countries' national emission reduction obligations. A detailed description of the Clean Development Mechanism, and of how it works, can be found in section 2. This paper examines how the CDM affects the international provision equilibrium of GHG abatement and the welfare of the countries involved.

I use a non-cooperative Nash game, in a public good provision framework, to model the strategic interaction between an industrialized and a developing country. Environmental protection in the form of emission reduction is seen as a global public good that is privately provided by entities from the industrialized or developing respectively emerging country. Both countries can contribute to global abatement, and both countries are assumed to value abatement positively, but the industrialized country assigns a higher value to emission reduction than does the developing country.

The analysis of the public good game shows that both countries, the industrialized and the developing one, have a larger welfare with the CDM than without it. In addition, I find that under the CDM, that is, for cases in which the industrialized and the developing country can abate on the developing country's soil, the results strongly depend on which of the two has access to the least expensive abatement opportunities in the developing country. If the countries had a choice, each country would prefer for the other one to have access to the least expensive abatement opportunities, because this allows them to commit to low emission reductions.

The parties to the climate convention, who issued the Kyoto Protocol, pursue several goals; those being not only worldwide commitment to emission reduction,

\footnotetext{
${ }^{1}$ See Newell et al. (2013).
} 
but also the flow of support from rich, industrialized countries to poor, developing ones. The Clean Development Mechanism is intended to support both objectives. This paper shows that the realization of one goal or the other is entirely dependent on who has access to the least expensive abatement opportunities.

Methodologically, this paper is closest to the literature on the private provision of public goods. Major contributions to this literature were made by Cornes and Sandler (1985) and Bergstrom et al (1986). Hoel (1991) applied their model to environmental public goods. He showed that uncoordinated unilateral action, taken to reduce GHG emissions, can have negative effects on a country's negotiating position. Further, unilateral action might even lead to a larger amount of global emissions than self-interested actions by all countries.

In my paper institutional change leads to changes in the equilibrium outcome of the public good game. Likewise, in Konrad (1994), Buchholz and Konrad (1994), Buchholz and Konrad (1995), Ihori (1996) and Morath (2010) institutional change occurs and its implications are analyzed. Konrad (1994) introduces a period previous to the public good game, in which players can determine which fraction of their endowment shall be disposable income in the public goods game. He finds that this generates an incentive to strongly reduce disposable income and free-ride on richer individuals' contributions in the public good game.

In Buchholz and Konrad (1994) the players simultaneously choose their production technologies, prior to a simultaneous emission reduction game. Players have the incentive to choose a production technology that leads to high opportunity costs for abatement and therefore makes free-riding, in the second stage of the game, credible. Buchholz and Konrad (1995) and Ihori (1996) look at twocountry models in which the two players have different contribution productivities and therefore different contribution costs. Previous to the public good provision game, players can simultaneously choose to make an income transfer to the other player. Both papers find that the less productive agent has an incentive to transfer income to the more productive one, committing itself to low contributions in the public good provision game.

In Morath (2010) the players do not know the value of emission reduction. They can, however, publicly acquire information on the abatement value previously to a public good game of abatement. Morath finds that players can have an incentive to abstain from information acquisition. The reason for this is that information acquisition, which positively affects own contributions, can in return 
decrease other countries' contributions, if the own benefits from abatement are learned to be large. This strategic choice of information can have a negative effect on GHG abatement and efficiency.

All authors mentioned above deal with voluntary public good provision and most of them look at an environmental public good. They do, however, not address public good contributions that a player carries out abroad, which is the case for the Clean Development Mechanism. In this paper, in contrast, I abstract from the strategic interaction that occurs between countries that contribute to the global public good, emission reduction, by abating domestically and focus on the strategic interaction that occurs when a country cross border abates. That is, a country contributes to the public good, emission reduction, by abating abroad, in another country.

As I in this paper, Bréchet et al. (2011) analyze the Clean Development Mechanism but not in a public good game. They use a bargaining model to study the implications of the CDM on global emissions. Firms from an industrialized and a developing country join together for a CDM project. They bargain over each other's optimal investment level in clean technology, their carbon emission level and their respective shares of emission credits which they receive from the CDM project. The authors find that, when the firm from the developing country has a positive bargaining power, the CDM leads to an emission increase. Further, the authors examine the effect of adding a new country to the Kyoto Protocol that does not commit to any abatement target. They find that global emission reductions only occur if this new developing country has no bargaining power. In contrast to Bréchet et al. (2011) my focus is not on the interaction of firms that jointly engage in an abatement project nor on the effect the CDM has on global emissions. I concentrate on the strategic interaction between two GHG abating countries when, under the CDM, firms of the industrialized country can engage in abatement projects in the developing country and on the welfare implications this mechanism has.

Other literature on the CDM deals predominantly with the optimization of the Clean Development Mechanism. A recurring concern is to preserve the environmental integrity of the mechanism. The authors of the Kyoto Protocol intended for CDM projects to be additional to low-cost abatement projects, which are costefficient on their own and do not require the payment of emission credits, in the 
form of Certified Emission Reductions (CERs), to become economical. ${ }^{2}$ Many authors claim that this additionality is not warranted for a large proportion of CDM projects. As the host country does not have an emission restriction, extra emission credits, which are paid out for abatement that is not truly additional but would have also occurred in the absence of the CDM, might be created. Hence, instead of an emission reduction due to the CDM, the mechanism might lead to an increase in Green House Gas emissions. Intending to provide a solution to this problem a variety of authors assess new ways to measure the counterfactual, to which the abatement under the CDM shall add (Paulsson 2009). With this paper, I do not attempt to examine the additionality problem, but abstract from this problem to focus on the strategic interaction between two countries, when one of these countries does not only abate emissions at home but also in the other country.

The following section provides a broad illustration of the Clean Development Mechanism. Section 3 deals with the formal analysis of the CDM. It starts with a benchmark case, after which two cases with the CDM under different cost regimes are solved. Section 4 compares the model results in the different cases under normative aspects. Section 5 concludes the paper.

\section{The Institution CDM}

The description of the Clean Development Mechanism can be found in Article 12 of the Kyoto Protocol. It is intended to allow industrialized (Annex I) countries to reach their abatement obligations at the lowest possible cost, and developing or emerging (Non-Annex I) countries to profit from foreign investment and technology spill-overs. Annex I countries to the United Nations Framework Convention on Climate Change from 1992 (UNFCCC) are for the most part developed countries and to a lesser extent additional countries who likewise committed themselves to reducing their GHG emissions. ${ }^{3}$ The countries' intention in 1992 was to return

\footnotetext{
${ }^{2}$ In the literature, emissions and financial additionality are distinguished. The first measures whether or not emissions will be reduced compared to the counterfactual, the latter whether or not the CDM project would occur if not for the profits from CER sales. Both should be fulfilled to secure the integrity of the mechanism, see Paulsson (2009).

${ }^{3}$ Annex I countries are all OECD countries in the year 2013 less Chile, Israel, Korea and Mexico and plus Belarus, Bulgaria, Croatia, Latvia, Liechtenstein, Lithuania, Monaco, Romania, Russian Federation and Ukraine.
} 
to their emission levels from 1990 by the year 2000 (UNFCCC 1992). Non-Annex I countries are all the countries which have ratified the Kyoto Protocol but have not agreed to any GHG emission reduction target (Umweltbundesamt 2011).

With the CDM, Annex I countries, self-committed to a GHG emission cap, can take on abatement projects in Non-Annex I countries whose emissions are unbounded. Public or private entities from an Annex I country can initiate and/or invest in GHG abatement projects abroad. Corresponding to the units of emission reduction induced by the investments, the investing entity gains so called Certified Emission Reductions (CERs) (Umweltbundesamt 2011). These CERs are emission rights which the investor can sell or use to count against its own commitment (Paulsson 2009).

Ordinary production plants as well as hydro power stations or photovoltaic parks can qualify as CDM projects. Generally, any project is admissible as long as it generates an emission reduction compared to the respective business-as-usual scenario. The counterfactual business-as-usual scenario is what would happen in the absence of the CDM, either due to actions taken by entities from the developing country itself, those taken by foreign investors or those taken by both working together. ${ }^{5}$ These are also the constellations in which CDM projects can be carried out.

The business-as-usual scenario for the ordinary production plant could make use of antiquated and high-emission technology. In case of hydro power or photovoltaic stations, the business-as-usual scenario could be electricity generation by way of a coal power station. The counterfactual emissions in the business-as-usual scenario mark the baseline to which emissions of CDM projects are compared. The units mitigated compared to the baseline give the number of Certified Emission Reductions which are granted to the parties involved in the project (Greiner Michaelowa 2003). The share of Certified Emission Reductions each party gets depends on the share it invested in the abatement project (Bréchet et al. 2011). ${ }^{6}$

\footnotetext{
${ }^{4}$ Non-Annex I countries are predominantly developing and emerging countries. For a detailed list, see the web page of the United Nations Framework Convention on Climate Change.

${ }^{5}$ The entity which proposes the CDM project - either a developing or an industrialized country entity - has to state the amount of counterfactual GHG emissions and an explanation of how it calculated this number, in the Project Design Document. This document is then reviewed by a Designated Operational Entity, for example a German TÜV and submitted to the CDM executive board.

${ }^{6}$ When Annex I countries abate emissions in a Non-Annex I country, the former cam team up and share the CERs. Likewise, in the case of joint projects between a Non-Annex I country
} 
For illustration purposes, the CDM shall be explained by a real life example. The German RWE AG, one of Europe's largest electric utilities companies, frequently engages in CDM projects with Chinese firms. One of these projects is the "Coke Dry Quenching Waste Heat Recovery for Power Generation" project in the Chinese city of Laiwu. In May 2004 Laiwu Iron \& Steel Group Corp. decided to build a power generation plant with turbines that run on steam, heated by hot inert gas. ${ }^{7}$ However, the internal rate of return for the project was viewed as too low, so Laiwu Iron \& Steel decided to register their undertaking as a CDM project. At first, the Chinese company had to find an Annex I entity willing to buy the Certified Emission Reductions that the project would generate. They found RWE AG. To participate in the CDM project both companies had to get authorization from their respective government bodies: the German Federal Environmental Agency's Emission Trading Authority in Germany and, in China, the National Development and Reform Commission of the Peoples Republic of China. With the application, Laiwu Iron \& Steel submitted a comprehensive Project Design Document explaining the planned activity and stating a detailed operating plan and the expected emission reduction compared to the business-as-usual scenario. The document describes in great detail how the business-as-usual scenario comes about and why the emission reduction by the project is truly additional to the counterfactual one. The CDM executive board is the UNFCCC's entity in charge of all CDM projects. For monitoring purposes, however, the executive board hires private contractors: the so called Designated Operational Entities. One Designated Operational Entity revises the project, based on its Project Design Document, and recommends the approval to the CDM executive board. This was TÜV NORD CERT GmbH in the example. A different Designated Operational Entity oversees the project, visits the project site and validates the actual emission reductions. In the example, this Designated Operational Entity was TÜV SÜD Industrie Service GmbH. Therefore, TÜV SÜD is also the entity which certifies the emission reductions that are generated. The project is expected to generate emission reductions of 326.309 metric tons of carbon dioxide equivalent per annum (CDM project no. 1656: Coke Dry Quenching Waste Heat Recovery for Power Generation Project

and one or several Annex I countries, the Non-Annex I country and the Annex I countries will all receive CERs.

${ }^{7}$ The hot inert gas is a byproduct of the coke dry quenching. Cold inert gas enters the dry quenching oven but is not consumed. The hot inert gas then exits the oven, heats a boiler for the steam production, cools down and again enters the dry quenching oven. 
of Laiwu Iron \& Steel Group Corp.).

The majority of CDM projects is similar to this example. An entity from a developing country wants to carry out a CDM project and finds itself an industrialized partner to buy the generated Certified Emission Reductions. However, other projects exist where the industrialized partner invests not only money but also know-how. In some cases the project participants are a firm in an industrialized country and its developing country subsidiary.

The intention of the Kyoto authors was that only additional abatement, which adds to the counterfactual, should occur as CDM abatement. That is, only high cost abatement projects should be registered with the UNFCCC. However, empirical evidence shows otherwise. ${ }^{8}$ Therefore, I will not only consider the intended case, but also the reversed one, where CDM projects are the low cost projects.

\section{Formal Analysis}

Consider a game with two players, countries $I$ and $D . \quad I$ is an industrialized (Annex I) country and $D$ a developing (Non-Annex I) country. ${ }^{9}$ Each of the two players, $I$ and $D$, simultaneously chooses its amount of emission reduction. For simplicity, I assume that country $I$ can abate in $I$ and in $D$, while country $D$ can only abate in $D .{ }^{10}$ Player $I^{\prime} s$ set of possible actions is to choose $x_{I I} \in[0, \infty)$ and $x_{I D} \in[0, \infty)$. The variable $x_{I I}$ denotes the amount of emission reduction country $I$ realizes at home, and $x_{I D}$ is the emission reduction country $I$ realizes in country $D$. Player $D^{\prime} s$ set of possible actions is to choose $x_{D D} \in[0, \infty)$, the amount of emission reduction country $D$ realizes at home. This model explains all types of CDM projects mentioned in section 2. It is applicable to projects where money is transferred from the industrialized to the developing country to finance abatement there, as well as to projects where physical labor and/or know-how is transferred

\footnotetext{
${ }^{8}$ See for example Haya (2009). She surveys the general use of the CDM in India and specific abatement projects in India and China and finds that the majority of the examined CDM projects are not additional.

${ }^{9}$ Strictly speaking, firms are the ones making the abatement decisions. However, the countries determine the amount of emission allowances the firms receive. The firms can trade these allowances. So, in the end, the amount of abatement is determined by the emission quotas set by the Annex I countries and the market mechanism. Here, for simplicity and as is common in the literature (see for example Hoel (1991)), I let the countries make the abatement decision.

${ }^{10} D^{\prime} s$ not abating in $I$ reproduces the Clean Development Mechanism and would also be the equilibrium outcome of a model in which $D$ can also abate in $I$.
} 
from the industrialized to the developing country for abatement purposes.

Emission reductions by countries $I$ and $D$ are contributions to a global public good. The payoff function from these public good contributions is the welfare function of country $I$ for player $I$ and the welfare function of country $D$ for player $D$. Player $I^{\prime} s$ payoff is

$$
W_{I}=v_{I}\left(x_{I I}+x_{I D}+x_{D D}\right)-c_{I}\left(x_{I I}, x_{I D}, x_{D D}\right)
$$

and player $D^{\prime} s$ payoff is

$$
W_{D}=v_{D}\left(x_{I I}+x_{I D}+x_{D D}\right)-c_{D}\left(x_{I D}, x_{D D}\right) .
$$

The parameters $v_{I}$ and $v_{D}$ are player $I^{\prime} s$ and $D^{\prime} s$ marginal willingness to pay for abatement. I assume that the players' marginal willingness to pay for abatement is constant and that both countries $I$ and $D$ attribute a positive value to GHG reduction, but country $I$ has a higher marginal willingness to pay for abatement than country $D, v_{I}>v_{D}>0 .{ }^{11}$ I assume complete information.

The players have to exert abatement costs for each unit of emission reduction. The higher the amount of abatement that was already carried out in a country, the higher are the abatement costs for one additional unit of abatement in this country. That is, the abatement cost function in country $I$ must be increasing and convex in $x_{I I}$, and the abatement cost function in $D$ must be increasing and convex in $x_{I D}$ and $x_{D D}$. For simplicity, I assume quadratic cost functions for the two countries and that these functions are symmetric. For convex costs, one can think of a variety of abatement projects ordered by abatement efficiency. That is, when little abatement has occurred so far, the efficient projects are still available for implementation. Large amounts of GHG reduction can be carried out at little costs. The more abatement has already occurred, the smaller the efficiency of the abatement projects that are still available. That is, high costs have to be paid for little amounts of GHG reduction.

In the absence of the Clean Development Mechanism, cross border abatement does not occur. That is, $x_{I D}=0$. I assume abatement costs in country $I$ to be

\footnotetext{
${ }^{11}$ I deliberately use constant marginal benefits of abatement, to abstain from modeling the strategic effects of country $I^{\prime} s$ and country $D^{\prime} s$ global abatement decisions, which of course exist when two parties contribute to the same global public good, to focus on the strategic interaction that takes place under the CDM between countries $I$ and $D$ in country $D$.
} 
a quadratic function of $x_{I I}$ and abatement costs in country $D$ to be a quadratic function of $x_{D D}$. With the CDM, however, both countries can abate in $D$, while in $I$ still only $I$ can abate. That is, $x_{I D} \in[0, \infty)$. Further, the cost functions that the countries face in $D$ then depend on which of the two has access to the least expensive abatement opportunities. In the following, having access to the least expensive abatement opportunities will be called having a preferential right for abatement in $D$, see figure 3.1.

In the countries' cost functions, the parameter $\gamma \in\{0,1\}$ indicates who holds the preferential right. If country $I$ has the preferential right, $\gamma=0$, if country $D$ has it, $\gamma=1 .^{12}$

Figure 3.1: Cost function in country $D$ with CDM

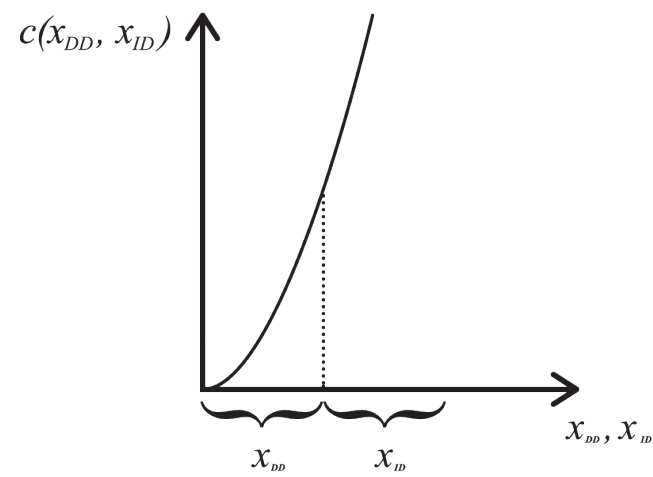

$D$ has preferential right in $D(\gamma=1)$

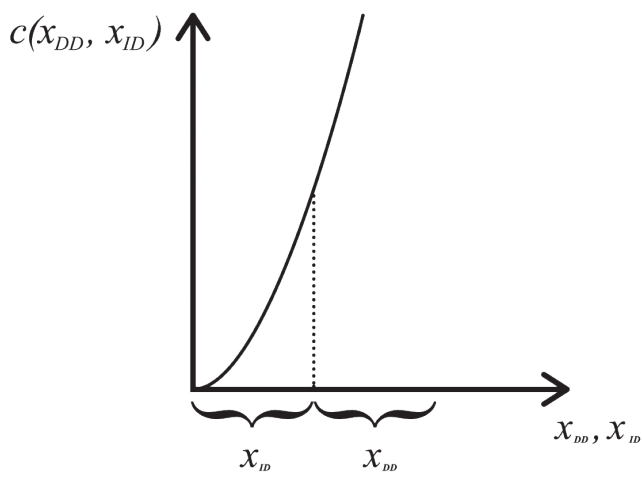

I has preferential right in $D(\gamma=0)$

So the general cost function for player $I$ is

$$
c_{I}\left(x_{I I}, x_{I D}, x_{D D}\right)=x_{I I}^{2}+\left(x_{I D}+\gamma x_{D D}\right)^{2}-\gamma^{2} x_{D D}^{2}
$$

That is, player $I^{\prime} s$ abatement costs are quadratic in $I^{\prime} s$ domestic abatement $x_{I I}$ and in $I^{\prime} s$ abatement abroad $x_{I D}$ but increase linearly in country $D^{\prime} s$ abatement $x_{D D}$. This implies that with every additional unit of abatement by $D$, country $I^{\prime} s$ marginal costs for abatement in $D$ increase.

Player $D^{\prime} s$ cost function is

\footnotetext{
${ }^{12}$ Abatement by countries $I$ and $D$ in $D$ are substitutes. To illustrate this with an example, one can think of solar panels, being installed on house tops. Once every roof is filled with solar panels, this technology is exhausted.
} 


$$
c_{D}\left(x_{D D}, x_{I D}\right)=\left(x_{D D}+(1-\gamma) x_{I D}\right)^{2}-(1-\gamma)^{2} x_{I D}^{2}
$$

Player $D^{\prime} s$ abatement costs are quadratic in its own abatement $x_{D D}$ and linearly increasing in country $I^{\prime} s$ abatement in $D, x_{I D}$. That is, with every additional unit of abatement by $I$ in $D$, country $D^{\prime} s$ marginal abatement costs increase.

I derive the Nash equilibrium outcomes for three different cases and compare these outcomes to each other. I start with the Benchmark Case without CDM, where both countries can only abate domestically. The other two cases are with CDM. In one of these cases, $D$ has a preferential right with regards to emission abatement in country $D(\gamma=1)$. In the other one, $I$ enjoys a preferential right for its abatement in $D(\gamma=0){ }^{13}$

With the two CDM cases, I look at borderline cases. There also exists a variety of cases in between the two, with all kinds of alignments of country $I^{\prime} s$ and $D^{\prime} s$ respective abatement projects on the cost function in $D$.

\subsection{Benchmark Case without CDM}

Suppose both countries $I$ and $D$ can only abate at home; that is, $x_{I D}=0$. Then player $I^{\prime} s$ objective function reduces to

$$
\max _{x_{I I}} W_{I}=v_{I}\left(x_{I I}+x_{D D}\right)-x_{I I}^{2},
$$

and player $D^{\prime} s$ to

$$
\max _{x_{D D}} W_{D}=v_{D}\left(x_{I I}+x_{D D}\right)-x_{D D}^{2} .
$$

It follows directly that optimal contributions are

$$
x_{I I}^{*}=\frac{v_{I}}{2} \text { and } x_{D D}^{*}=\frac{v_{D}}{2} .
$$

\footnotetext{
${ }^{13}$ The cases where one or the other player has a preferential right are not to be mistaken for cases with sequential moves. The contribution of the other country is unknown when countries decide on their own contribution. The preferential right is not a right to move first, but one which ensures a country to have lower marginal abatement costs in $D$ than the other country. The first mover in the sequential case would, to the contrary, not use its first mover advantage to secure the relatively lower marginal abatement costs for itself.
} 
Due to the constant marginal benefit of abatement, optimal abatement choices do not depend on the other country's abatement level. The resulting payoffs are

$$
W_{I}^{*}=\frac{v_{I}^{2}}{4}+\frac{v_{I} v_{D}}{2}
$$

and

$$
W_{D}^{*}=\frac{v_{D}^{2}}{4}+\frac{v_{I} v_{D}}{2} .
$$

Both players contribute to the public good and both abate up to the point where the marginal costs of abatement match the respective player's marginal willingness to pay, $v_{I}$ and $v_{D}$. While the players' abatement costs are symmetric, player $I^{\prime} s$ optimal amount of abatement is larger than player $D^{\prime} s$ as by assumption $I$ has a higher marginal benefit from GHG reduction than $D$ does.

\subsection{Effect of the Clean Development Mechanism}

In the following, I consider the optimal abatement choices if the Clean Development Mechanism is implemented and cross border abatement is possible for player $I$. Therefore, player $I$ faces abatement opportunities in countries $I$ and $D$, while player $D$ still only abates in $D$. That is, $x_{I D} \in[0, \infty)$.

\subsubsection{Preferential right for country $D$}

Suppose country $D$ enjoys a preferential right with respect to emission reduction. Intuitively this means that $D$ is allowed to invest in the least expensive abatement opportunities in $D$, while $I$ is only allowed to abate in excess of player $D^{\prime} s$ abatement. This is the scenario which corresponds to the one intended by the Kyoto authors. Abatement under the CDM is in this case additional.

In the case where $D$ has a preferential right, the assumptions on the cost functions are such that player $I$ has higher marginal costs than player $D$, when abating in country $D$. As $\gamma=1$, player $I^{\prime} s$ and $D^{\prime} s$ objective functions are

$$
W_{I}=v_{I}\left(x_{I I}+x_{I D}+x_{D D}\right)-x_{I I}^{2}-\left(x_{I D}+x_{D D}\right)^{2}+x_{D D}^{2}
$$

and

$$
W_{D}=v_{D}\left(x_{I I}+x_{I D}+x_{D D}\right)-x_{D D}^{2} .
$$


From the first order conditions for $I, v_{I}=2 x_{I I}$ and $v_{I}=2\left(x_{I D}+x_{D D}\right)$, and for $D, v_{D}=2 x_{D D}$, the following equilibrium contributions are derived:

$$
x_{I I}^{*}=\frac{v_{I}}{2}, x_{I D}^{*}=\frac{v_{I}-v_{D}}{2} \text { and } x_{D D}^{*}=\frac{v_{D}}{2} .
$$

These abatement choices constitute a unique Nash equilibrium. The equilibrium welfare for players $I$ and $D$ is,

$$
W_{I}^{*}=\frac{v_{I}^{2}}{2}+\frac{v_{D}^{2}}{4}
$$

and

$$
W_{D}^{*}=v_{I} v_{D}-\frac{v_{D}^{2}}{4}
$$

Player $D$ exerts the same amount of abatement as in the Benchmark Case. In country $I$, player $I$ still simply chooses the amount of abatement that maximizes $I^{\prime} s$ welfare under isolation. In addition, player $I$ adds to $D^{\prime} s$ abatement projects, in country $D$, up to the point where its own marginal willingness to pay equals the marginal abatement costs in country $D$. Therefore it is player $I^{\prime} s$ additional abatement that leads to larger global contributions than in the Benchmark Case. The same holds for global welfare.

\subsubsection{Preferential right for country $I$}

Suppose country $I$ enjoys a preferential right with respect to emission reduction. Intuitively this means that $I$ is allowed to invest in the least expensive abatement opportunities in $D$, while $D$ can only abate in excess of player $I^{\prime} s$ abatement in $D$. This is the scenario the Kyoto authors intended to prevent but which is nonetheless observed empirically. Abatement under the CDM is in this case non-additional.

In the case where $I$ has a preferential right, the assumptions on the cost functions are such that player $D$ has higher marginal costs than player $I$, when abating in country $D$. That is, $\gamma=0$. So player $I^{\prime} s$ and $D^{\prime} s$ objective functions are

$$
W_{I}=v_{I}\left(x_{I I}+x_{I D}+x_{D D}\right)-x_{I I}^{2}-x_{D I}^{2}
$$

and

$$
W_{D}=v_{D}\left(x_{I I}+x_{I D}+x_{D D}\right)-\left(x_{I D}+x_{D D}\right)^{2}+x_{I D}^{2}
$$


From the first order conditions for $I, v_{I}=2 x_{I I}$ and $v_{I}=2 x_{I D}$, and for $D$, $v_{D}=2\left(x_{I D}+x_{D D}\right)$, the following equilibrium contributions are derived:

$$
x_{I I}^{*}=\frac{v_{I}}{2}, x_{I D}^{*}=\frac{v_{I}}{2} \text { and } x_{D D}^{*}=0 .
$$

Player $D^{\prime} s$ optimal abatement choice results in a corner solution as by definition $x_{D D} \in[0, \infty)$. The abatement choices constitute a unique Nash equilibrium and the equilibrium welfare for players $I$ and $D$ is,

$$
W_{I}^{*}=\frac{v_{I}^{2}}{2}
$$

and

$$
W_{D}^{*}=v_{I} v_{D}
$$

Player $I$ abates in country $D$ up to the point where his marginal benefits from abatement are equal to his marginal abatement costs in $D$. As player $D$ has lower marginal benefits from abatement than player $I$ does, $D$ will not choose any abatement at all. That is, player $I^{\prime} s$ GHG reduction in country $D$ fully crowds out player $D^{\prime} s$ abatement. Player $D$ free-rides on $I^{\prime} s$ emission reductions.

\section{Welfare Comparison}

To assess the Clean Development Mechanism from a welfare perspective, I compare the countries' welfare in the three different cases. Firstly, the welfare in the absence of the mechanism is compared to the welfare under the mechanism. Secondly, I examine how the countries' welfare differs in the cases where country $I$ (country $D$ ) enjoys the preferential right regarding GHG abatement in country $D$.

\section{Proposition 1.}

a) Country $D^{\prime} s$ welfare is strictly higher under the CDM than without the $C D M$.

b) If $\gamma=1$, country I's welfare is strictly higher under the CDM than without the $C D M$.

If $\gamma=0$, country $I^{\prime} s$ welfare is strictly higher under the CDM than without the $C D M$, if and only if $v_{I}>2 v_{D}$. 
Proof.

a) Let $D$ have a preferential right. With the CDM player $D^{\prime} s$ welfare is strictly higher than without the CDM since the difference between 3.6 and 3.4 is $\frac{v_{I} v_{D}}{2}-\frac{v_{D}^{2}}{2}$ which is strictly positive.

Let $I$ have a preferential right. With the CDM, player $D^{\prime} s$ welfare is strictly higher than without the CDM since the difference between 3.8 and 3.4 is $\frac{v_{I} v_{D}}{2}-\frac{v_{D}^{2}}{4}$ which is strictly positive.

b) Let $D$ have a preferential right $(\gamma=1)$. With the CDM, player $I^{\prime} s$ welfare is strictly higher than without the CDM since the difference between 3.5 and 3.3 is $\left(\frac{v_{I}}{2}-\frac{v_{D}}{2}\right)^{2}$ which is strictly positive.

Let $I$ have a preferential right $(\gamma=0)$. With the CDM, player $I^{\prime} s$ welfare is strictly higher than without the CDM, iff $v_{I}>2 v_{D}$ since the difference between 3.7 and 3.3 is $v_{I}\left(\frac{v_{I}}{4}-\frac{v_{D}}{2}\right)$ which is strictly positive iff $v_{I}>2 v_{D}$.

Proposition 1 implies that with the CDM emission reductions in country $D$ increase compared to the Benchmark Case, due to player $I^{\prime} s$ cross border abatement in country $D$. At the same time, domestic emission reductions by players $D$ and $I$ remain constant compared to the Benchmark Case, if $D$ has a preferential right. If, however, $I$ has a preferential right player $D$ reduces his abatement contributions to zero compared to the Benchmark Case, but player $I$ overcompensates this reduction with his cross border abatement such that overall emission reductions are the same in the two cases with CDM.

While in the case where $D$ has the preferential right, with emission reductions also abatement costs stay the same for player $D$, in the case where $I$ has a preferential right abatement costs drop to zero together with $D^{\prime} s$ emission reductions. The increase in overall abatement, together with unchanged or decreased abatement costs, compared to the Benchmark Case, leads to a larger welfare under the CDM than without the CDM for country $D$.

Like country $D$, also country $I$ profits from the increased abatement compared to the Benchmark Case. However, as this abatement increase is due to player $I^{\prime} s$ cross border abatement in country $D$, player $I$ is the one who has to pay the costs for the increase in emission reductions.

If $\gamma=1$ that is, $D$ has a preferential right domestic abatement by countries $D$ and $I$ remains the same as in the Benchmark Case and $I^{\prime} s$ cross border abatement simply adds to the Benchmark Case abatement. Under the initial assumption that 
$v_{I}>v_{D}$, the additional benefits from this cross border abatement exceed player $I^{\prime} s$ additional abatement costs and country $I^{\prime} s$ welfare is higher under the CDM than without the CDM.

If $\gamma=0$ that is, $I$ has a preferential right domestic abatement by country $I$ remains the same as in the Benchmark Case, while $D^{\prime} s$ emission reductions drop to zero. As player $I$ fully compensates this drop and, further, adds the same amount of abatement as in the $D$ has a preferential right case, the additional abatement costs for $I$ are higher in the case where $I$ has a preferential right than in the case where $D$ has a preferential right; further, the condition under which additional benefits exceed additional costs is stronger in the latter case. That is, country $I^{\prime} s$ welfare is higher under the CDM than without the CDM only if $v_{I}>2 v_{D}$. When this condition is fulfilled, however, the CDM leads to a Pareto improvement.

In turn, if the two countries' willingness to pay for abatement was quite similar - i.e. while $v_{I}>v_{D}$, also $v_{I}<2 v_{D}$ - cost benefit considerations would detain country $I$ from cross border abatement in the case where $I$ has a preferential right. Country $I$ then rather leaves the abatement in $D$ to country $D$ because the supplementary abatement $I$ could take on in $D$ would not add enough benefits to compensate for the additional costs.

I have now analyzed how the welfare in the two cases with CDM compares to the welfare in the Benchmark Case. What remains to be seen is which of the two cases with CDM the countries $D$ and $I$ prefer.

\section{Proposition 2.}

a) Country $D^{\prime}$ s welfare is strictly lower in the case where D has a preferential right than in the case where I has a preferential right.

b) Country I's welfare is strictly higher in the case where D has a preferential right than in the case where I has a preferential right.

Proof.

a) Comparing 3.6 and 3.8 shows directly that $D^{\prime} s$ welfare is strictly lower when $D$ has a preferential right than when $I$ has a preferential right. The difference between 3.6 and 3.8 is $-\frac{v_{D}^{2}}{4}$ which is strictly negative.

b) Comparing 3.5 and 3.7 shows directly that $I^{\prime} s$ welfare is strictly higher when $D$ has a preferential right than when $I$ has a preferential right. The difference between 3.5 and 3.7 is $v_{D}^{2}$ which is strictly positive. 
Proposition 2 implies that if country $D$ could decide on the allocation of the preferential right, it would always opt for $I$ to have the preferential right. Likewise, when country $I$ could decide on the allocation of the preferential right, it would always opt for $D$ to have the preferential right. That is, both players prefer the case in which they themselves have higher marginal abatement costs in country $D$ than the other player does.

Overall emission reductions and therewith the two countries' benefits from abatement are the same in both cases. Player $D$ abates a positive amount when he has the preferential right but does not abate at all when player $I$ has the preferential right. That is, $D^{\prime} s$ abatement costs are positive in the former and nil in the latter case. With equal benefits form abatement in the two cases, country $D^{\prime} s$ welfare is, therefore, strictly lower when $D$ has the preferential right than when $I$ has the preferential right.

Player $I$ adds to $D^{\prime} s$ abatement when $D$ has the preferential right, but when $I$ has the preferential right $I$ not only compensates for $D^{\prime} s$ abatement from the $D$ has a preferential right case, but also adds the same amount as $I$ contributes in the $D$ has a preferential right case. That is, $I$ abates more in the $I$ has a preferential right case than in the $D$ has a preferential right case. Therefore, his abatement costs are higher in the former than the latter case. With equal benefits form abatement in the two cases, country $I^{\prime} s$ welfare is therefore strictly higher when $D$ has the preferential right than when $I$ has the preferential right.

Global welfare is the same in both cases with CDM. That is, when moving from one case to the other, welfare is simply redistributed from one country to the other.

\section{Conclusion}

The analysis of the simultaneous moves game shows that both countries involved in CDM projects have a higher welfare with the Clean Development Mechanism than without it. Also, global abatement is larger with the mechanism than in its absence. Regarding the industrialized country, welfare is only larger for a parameter range where the industrialized country's willingness to pay for abatement is substantially larger than the developing country's willingness to pay for abatement. With respect to the two different cost scenarios under the CDM that I have 
looked at, the two countries have antithetic preferences. Both countries prefer the scenario in which they themselves have higher marginal abatement costs than the other country. Therefore, the industrialized country would pick the $D$ has a preferential right case, while the developing country would decide on the $I$ has a preferential right case if it had a choice. When the industrialized country has the preferential right, the developing country can fully free-ride on the industrialized country's contributions, and its own abatement drops to zero.

For future climate negotiations, the results indicate that the Clean Development Mechanism should be kept as a GHG offset mechanism. The developing country always profits from it. Further, there are parameter ranges for which the industrialized country does also profit from the mechanism, and GHG emissions do always decrease.

The parties to the climate convention can pursue different goals. They could wish to get every country, including developing ones, to contribute, or they might wish to increase contributions, but spare the developing countries, and have the industrialized countries carry the burden. Depending on the goal, the parties to the convention have two different scenarios to choose from. If they grant a preferential right regarding abatement in the developing country to the developing country, both countries will contribute; that is, the developing country carries part of the burden. However, if the preferential right with respect to abatement in the developing country is granted to the industrialized country, the only country contributing will be the industrialized one. That is, at the same overall amount of global abatement, the industrialized country takes on all the abatement and the developing country is fully unburdened. 


\section{References}

[1] Cdm project 1656: Coke dry quenching waste heat recovery for power generation project of laiwu iron \& steel croup corp. http://cdm.unfccc.int/projects/db/tuev-sued1204555019.02/view (accessed 06.06.2012).

[2] T. Bergstrom, L. Blume, and H. Varian. On the private provision of public goods. Journal of Public Economics, 29:25-49, 1986.

[3] T. Bréchet, Y. Ménière, and P.M. Picard. The clean development mechanism in a globalized carbon market. CREA Discussion Paper, 2011.

[4] W. Buchholz and K.A. Konrad. Global environmental problems and the strategic choice of technology. Journal of Economics, 3:299-321, 1994.

[5] W. Buchholz and K.A. Konrad. Strategic transfers and private provision of public goods. Journal of Public Economics, 57:489-505, 1995.

[6] R. Cornes and T. Sandler. The simple analytics of pure public good provision. Economica, 52:103-116, 1985.

[7] S. Greiner and A. Michaelowa. Defining investment additionality for cdm projects-practical approaches. Energy Policy, 31:1007-1015, 2003.

[8] B. Haya. Measuring emissions ageinst an alternative future: Fundamental flaws in the structure of the kyoto protocol's clean development mechanism. http://ssrn.com/abstract=1562065 (24.10.2011) Energy and Resources Group Working Paper ERG09-001, December 2009.

[9] M. Hoel. Global environmental problems: The effects of unilateral actions taken by one country. Journal of Environmental Economics and Management, 20:55-70, 1991.

[10] T. Ihori. International public goods and contribution productivity differentials. Journal of Public Economics, 61:139-154, 1996.

[11] K.A. Konrad. The strategic advantage of being poor: Private and public provision of public goods. Economica, 61:79-92, 1994. 
[12] F. Morath. Strategic information acquisition and the mitigation of global warming. Journal of Environmental Economics and Management, 59:206217, 2010 .

[13] R. Newell, W. Pizer, and D. Raimi. Carbon markets 15 years after kyoto: Lessons learned, new challenges. Journal of Economic Perspectives, 27:123146, 2013.

[14] E. Paulsson. A review of the cdm literature: from fine-tuning to critical scrutiny? International Environmental Agreements, 9:63-80, 2009.

[15] Umweltbundesamt. Projektbezogene internationale klimaschutzmechanismen - clean development mechanism und joint implementation. [online], available: http://www.umweltbundesamt-daten-zurumwelt.de/umweltdaten/public/theme.do?nodeident $=5777$ [13 sep 2011]. 2011.

[16] UNFCCC. United nations framework convention on climate change. [online], available: http://unfccc.int/resource/docs/convkp/conveng.pdf [24 sep 2012]. 1992. 